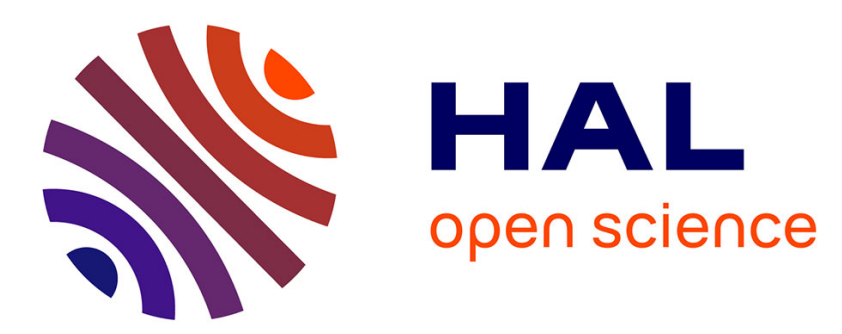

\title{
Preparation of cobalt polyporphine and its catalytic properties in oxygen electroreduction
}

\author{
D. V Konev, K. V Lizgina, D. K Khairullina, M. A Shamraeva, Charles H. \\ Devillers, M. A Vorotyntsev
}

\section{- To cite this version:}

D. V Konev, K. V Lizgina, D. K Khairullina, M. A Shamraeva, Charles H. Devillers, et al.. Preparation of cobalt polyporphine and its catalytic properties in oxygen electroreduction. Elektrokhimiya / Russian Journal of Electrochemistry, 2016, 52 (8), pp.778-787. 10.1134/S1023193516060069 . hal03471752

\section{HAL Id: hal-03471752 \\ https://hal.science/hal-03471752}

Submitted on 9 Dec 2021

HAL is a multi-disciplinary open access archive for the deposit and dissemination of scientific research documents, whether they are published or not. The documents may come from teaching and research institutions in France or abroad, or from public or private research centers.
L'archive ouverte pluridisciplinaire HAL, est destinée au dépôt et à la diffusion de documents scientifiques de niveau recherche, publiés ou non, émanant des établissements d'enseignement et de recherche français ou étrangers, des laboratoires publics ou privés. 


\title{
Preparation of Cobalt Polyporphine and Its Catalytic Properties in Oxygen Electroreduction
}

\author{
D. V. Konev ${ }^{a, b}, *$, K. V. Lizgina ${ }^{c, * *}$, D. K. Khairullina ${ }^{b}$, M. A. Shamraeva ${ }^{c}$, \\ C. H. Devillers ${ }^{d}$, and M. A. Vorotyntsev ${ }^{a, b, c, d}$ \\ anstitute of Problems of Chemical Physics, Russian Academy of Sciences, Chernogolovka, Moscow oblast, Russia \\ ${ }^{b}$ Mendeleev Institute of Chemical Technology of Russia, Moscow, Russia \\ ${ }^{c}$ Moscow State University, Moscow, Russia \\ ${ }^{d}$ Institut de Chimie Moléculaire, Université de Bourgogne et Franche-Comté, Dijon, France \\ *e-mail:dkfrvzh@gmail.com \\ **e-mail: ks09@inbox.ru \\ Received September 10, 2015
}

\begin{abstract}
A new member of the polyporphine series—cobalt polyporphine of type I (pCoP-I)—was prepared from the starting magnesium polyporphine of type I (pMgP-l) by ion exchange, i.e. by sequential processing of the pMgP-I polymer film on the electrode surface with solutions of trifluoroacetic acid (forming metalfree polyporphine of type $\mathrm{I}, \mathrm{pH}_{2} \mathrm{P}-\mathrm{I}$ ) and cobalt(II) acetate in organic solvents. The completeness of each stage of ion exchange can be judged from the change in the electrochemical and spectral characteristics of the obtained polymer films of unsubstituted porphine $\left(\mathrm{pH}_{2} \mathrm{P}-\mathrm{I}\right)$ and cobalt porphine $(\mathrm{pCoP}-\mathrm{I})$ of type I. Oxidative transformation of this polyporphine $\mathrm{pCoP}-\mathrm{I}$ was performed, which led to the formation of additional bonds between the neighboring porphine units in the polymer film (transition of polymer of type I into polymer of type II, pCoP-II). The behavior of the polymer films of cobalt polyporphine of types I and II in oxygen electroreduction was studied. The films showed catalytic activity in this process.
\end{abstract}

Keywords: electropolymerization, porphine, metal porphines, conductive polymer, oxygen electroreduction, polymer-modified electrodes

DOI: 10.1134/S1023193516060069

\section{INTRODUCTION}

In recent decades, porphyrin systems have received much attention due to their unique chemical and physicochemical properties [1-3]. Of great interest is their immobilization in the form of an electroactive film on solid electrode surfaces for further use as electrocatalysts and sensor devices. The set of polymer materials of this kind can be expanded by seeking new porphyrin monomer units $[4,5]$, varying the polymerization conditions $[6,7]$, or using chemical modification/functionalization of polymer structures obtained in any way [8].

In recent years, the first representatives of the new family of electroactive materials have been obtained. These are polymers of porphine monomer units linked either by meso-meso single bonds (polyporphines of type I (pMP-I), Fig. 1a) or by three (meso-meso and two beta-beta) bonds (polyporphines of type II (pMP-II), Fig. 1b) [9-11]. The polymer of type I, pMgP-I, is the product of direct electropolymerization of magnesium porphine on the electrode surface at a potential corresponding to the first oxidation wave of the MgP monomer. As a result of the irreversible oxidative transformation at higher potentials, addi- tional bonds are formed in the polymer film, and the polymer acquires a condensed structure and unique (for conductive polymers) properties [10, 12].

The $\mathrm{Mg}^{2+}, \mathrm{H}^{+}$, and $\mathrm{Zn}^{2+}$ ions having no redox activity served as coordinated ions inside the porphine rings (M). The size and properties of $\mathrm{Zn}^{2+}$ ion are similar to those of the starting $\mathrm{Mg}^{2+}$ ion $[13,14]$. To expand the new class of electroactive materials that are promising for various potential applications, it is of interest to introduce transition metals in the polymer structure of pMP that would impart electrocatalytic properties to the polyporphine matrix.

The first stage of this study is preparation of cobalt polyporphine of type I (pCoP-I) based on the pMgP-I polymer film [9] on the electrode surface by ion exchange [13-16] followed by the oxidative transformation of this polymer into the corresponding polymer of type II pCoP-II [10]. Direct polymerization of $\mathrm{H}_{2} \mathrm{P}$ and CoP monomers is difficult because of their low solubility and high oxidation potential [14]. In addition, direct oxidation of these compounds leads to the formation of a low-conjugate structure with mesobeta and/or beta-beta binding of adjacent monomer 
units [17]. The chosen method (replacement of the central ion in preliminarily prepared magnesium polyporphine) makes it possible to obtain polymers with different central ions of the porphine ring, but with the same structure of macrochains.

As is known, molecular cobalt and iron porphyrines show a catalytic effect [18-21] in oxygen electroreduction. This property is also inherent in various electroactive materials containing a $\mathrm{MeN}_{4}$ unit, in which $\mathrm{Me}$ is a metal ion and the $\mathrm{N}_{4}$ ligand is a porphyrine or phthalocyanine heterocycle [22-24]. In contrast to the majority of such materials in which the porphine centers are grafted to the side chain [25, 26], separated by spacers [27-29], or are thermopolymers with an unknown structure [30], the polyporphine matrix has certain potential advantages when used in electrocatalysis. The main advantages are high density of active sites (heterocycles) in view of the absence of spacers and their incorporation in the main chain with high degree of conjugation, which provides electron transfer from the electrode to the metal complex. Therefore, the goal of the present study was to prepare electrodes modified with pCoP-I and pCoP-II films and test them in oxygen electroreduction in neutral and alkaline aqueous solutions.

\section{OBJECTS AND METHODS OF INVESTIGATION}

The object of investigation is a polymer film obtained by potentiostatic electropolymerization of magnesium porphine in an acetonitrile (AN) solution [11] at a potential of $0.35 \mathrm{~V}$. These conditions correspond to the formation of a structure of type I formed by porphine rings linked with one another by single bonds at the meso-positions (Fig. 1) and containing $\mathrm{Mg}^{2+}$ as a coordination ion (type I, pMgP-I) [31]. All the potentials are given relative to the $\mathrm{Ag}^{+} / \mathrm{Ag}$ reference electrode with a concentration of silver ions of $10 \mathrm{mM}$ in a supporting solution of $0.1 \mathrm{M} \mathrm{Bu}_{4} \mathrm{NPF}_{6}$ in AN (except Fig. 10, which relates to measurements in aqueous media relative to the saturated silver chloride electrode (SCE)). The potential difference of the metal ion electrode in acetonitrile and saturated SCE is $0.3 \mathrm{~V}$. The potential scan rate was $0.1 \mathrm{~V} / \mathrm{s}$ in all cyclic voltammetry (CV) studies.

The electrochemical studies were performed in a three-electrode cell. The auxiliary electrode was platinum wire, which was separated from the working space with a separating wall of sintered glass. The working electrodes were the transverse section of platinum wire or a glass carbon rod with isolated side surfaces and glass plates covered with an indium-tin oxide (ITO) layer with an area of $0.01,0.03$, and $0.6 \mathrm{~cm}^{2}$. The deposition charge of the films, which is proportional to their thickness according to [8], was $9-16 \mathrm{mC} / \mathrm{cm}^{2}$. The measurements were performed on Elins PI-50PRO-3 and Autolab 302N potentiostats. (a)

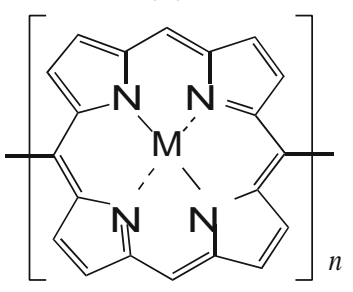

(b)

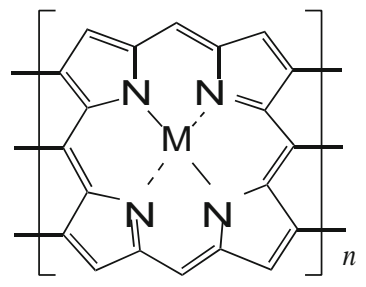

Fig. 1. Structure of polyporphines of types (a) I and (b) II; $\mathrm{M}: \mathrm{Mg}^{2+}, 2 \mathrm{H}^{+}, \mathrm{Zn}^{2+}$.

The absorption spectra of solutions and films in the visible and UV ranges were recorded on a Varian Cary 50 spectrophotometer.

The preparative treatment of the electrodes coated with pMgP-I films with the aim of introducing the cobalt(II) ion in them was performed by a procedure similar to the one described in $[13,14]$. At first the electrodes modified with magnesium polyporphine were submerged in a preliminarily deaerated solution of trifluoroacetic acid (TFA) in AN (at a ratio of $1: 50, \mathrm{v} / \mathrm{v}$ ) and then in a deaerated solution of cobalt(II) acetate tetrahydrate in dimethyl formamide (DMF) at a concentration of $10 \mathrm{mg} / \mathrm{mL}$ while heating the solution to $75-85^{\circ} \mathrm{C}$ on a sand bath. After the electrodes were kept in the indicated solutions for 5 min (TFA) and 6090 min (DMF), they were washed three times in AN (preliminarily in DMF to remove traces of cobalt acetate in the latter case) and placed in an electrochemical cell containing a deaerated solution of $0.1 \mathrm{M} \mathrm{Bu}_{4} \mathrm{NPF}_{6}$ to study the redox transitions of the polymer film.

For recording the IR spectra, the above-described procedures were performed using platinum foil with a thickness of $25 \mu \mathrm{m}$ as a working electrode. The spectra were recorded ex situ (after washing the film in acetonitrile and drying in air) by attenuated total reflection (ATR) spectrometry on a Bruker Vector 22 FTIR spectrophotometer with an MKII Golden Gate total reflection accessory. The samples for X-ray photoelectron spectroscopy (XPS) were prepared by a similar procedure. XPS studies were performed on an SIA100 spectrometer (Cameca Riber apparatus) using nonmonochromated Al Ka radiation (1486.6 eV).

The scanning electron microscopy (SEM) studies of the polymer film samples and energy dispersion (EDX) analysis of their element composition were performed on a JEOL JSM6400F scanning electron microscope with an Oxford Instruments EDS analyzer accessory.

\section{RESULTS AND DISCUSSION}

The magnesium polyporphine film of type I (pMgP-I) was synthesized from the corresponding MgP monomer on the surface of a solid electrode (the procedure was described in [11]) with subsequent pre- 


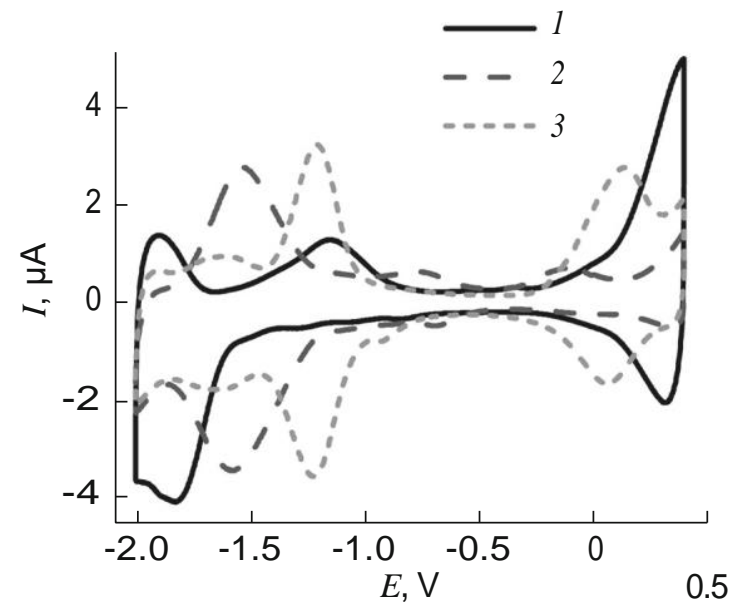

Fig. 2. Cyclic voltammetry of the polyporphine film on the surface of the platinum electrode in $0.1 \mathrm{M} \mathrm{Bu}_{4} \mathrm{NPF}_{6}$ (AN) at different stages of preparative treatment: (1) magnesium polyporphine film of type I prepared by the procedure of [11] with a lutidine addition in the polymerization solution, deposition charge $9.5 \mathrm{mC} / \mathrm{cm}^{2}$; (2) film 1 treated with a TFA solution in AN (1:50) for' 10 min (metal-free polyporphine of type I, $\mathrm{pH}_{2} \mathrm{P}-\mathrm{I}$ ), (3) film 2 treated with a DMF solution of $\mathrm{Co}(\mathrm{OAc})_{2} \cdot 4 \mathrm{H}_{2} \mathrm{O}$ with a concentration of $10 \mathrm{mg} / \mathrm{mL}$ for $60 \mathrm{~min}$ while heating it to $75-85^{\circ} \mathrm{C}$ (cobalt polyporphine of type I, pCoP-I).

parative treatment of the polymer film with salt solutions according to the scheme

$$
\begin{aligned}
& \text { / MgP }-E=0.35 \mathrm{VAN} \\
& \stackrel{\text { TFA AN }}{\rightarrow} \text { pH P-l }- \text { Co(OAc)2DMF } \\
& \begin{array}{l}
2 \\
2=1.0
\end{array}
\end{aligned}
$$

The films were studied by cyclic voltammetry, UV, visible, IR, and X-ray photoelectron spectroscopy, and scanning electron microscopy to confirm the inclusion of the cobalt ion with preservation of the structure of the porphyrine matrix and determine the degree of degradation of the latter during treatment. The results of studies are given below in the corresponding sections.

\section{Cyclic Voltammetry}

Figure 2 presents the cyclic voltammograms of the polymer film of type I (pMP-I, the structure shown in Fig. 1a) at different stages of the introduction of the new central ion. Curve 1 corresponds to the polymer film in the initial state pMgP-I [9-11]. This film has two electroactivity ranges corresponding to the potentials of the start of the transition of the MgP monomer unit to the radical anion $(\sim-1.75 \mathrm{~V})$ or radical cation $(\sim 0.25 \mathrm{~V})$ form during the reduction and oxidation, respectively. Curves 2 and 3 for polyporphine in the form of a free base $\left(\mathrm{pH}_{2} \mathrm{P}-\mathrm{I}\right)$ and cobalt polyporphine pCoP-I, respectively, are similar, both in form and redox charge, to the voltammogram of the starting film, which indicates that the films retained their integrity and electric contact with the electrode surface after preparative treatment with acid and salt solutions.

The characteristic feature of the changed voltammograms after the replacement of the central ion is the shift of the negative and positive charging potentials of

the polymer. As shown in [13], the value and direction of the shift correlate with the oxidation/reduction wave potentials of the corresponding MgTPP and $\mathrm{H}_{2}$ TPP monomer analogs (TPP is tetraphenylporphine).

Since $\mathrm{Mg}$ and $2 \mathrm{H}$ in the porphine ring do not show their own electroactivity, the electrons are transferred to the $\pi$-electron system of the porphine ring. For cobalt polyporphine whose central ion is a transition metal capable of oxidation/reduction in the given range of potentials, the observed redox transitions at $-1.2 \mathrm{~V}$ and $+0.1 \mathrm{~V}$ (curve 3, Fig. 2) should be attributed to the $\mathrm{Co}(\mathrm{I}) / \mathrm{Co}$ (II) and $\mathrm{Co}(\mathrm{II}) / \mathrm{Co}$ (III) processes based on comparison with the literature data for the CoTPP monomer [1].

After the electronic characteristics of the polymer films of type I (see below) were studied by proven methods [9, 11], all the three films were subjected to oxidative transformation in a galvanostatic mode (passing direct anodic current through the modified electrode until the potential reached $1 \mathrm{~V}$ in an acetonitrile solution of $0.1 \mathrm{M} \mathrm{Bu}_{4} \mathrm{NPF}_{6}$ ), which leads to the formation of a polymer with a cross-linked structure (type II). The detected expansion of the electroactivity range for polymers with $\mathrm{Mg}, 2 \mathrm{H}$, and $\mathrm{Zn}$ central atoms

[13] was also observed for the cobalt-containing polymer, while the redox signals obtained earlier were reproduced (Fig. 3). The resulting signal of the films of type II is close in intensity for all the three polymer films: pMgP-II, $\mathrm{pH}_{2} \mathrm{P}-\mathrm{II}$, and pCoP-II. Nevertheless, there are two additional peaks for the pCoP-II film, which corresponds to the transitions of the central ion $\mathrm{Co}(\mathrm{I}) / \mathrm{Co}(\mathrm{II})$ and $\mathrm{Co}(\mathrm{II}) / \mathrm{Co}(\mathrm{III})$. Thus, it is confirmed once again that the oxidation forms additional bonds between the neighboring porphine units, which lead to permanent electron delocalization and narrowing of the forbidden gap to zero with an increase in the number of chain links irrespective of the nature of the central atom [12, 32, 33].

\section{Spectral Studies}

The X-ray photoelectron spectra of pMP-I films shown in Fig. 4 suggest that demetallation leads to nearly complete removal of magnesium and its replacement by two hydrogen atoms. This is indicated by both the disappearance of the magnesium peak on passing from spectrum 1 to spectrum 2 and the change in the shape of the $\mathrm{N} 1 s$ peak corresponding to two (amine and imine) nitrogen forms in the heterocycle for $\mathrm{pH}_{2} \mathrm{P}-\mathrm{I}$. The introduction of the cobalt ion (spec- 


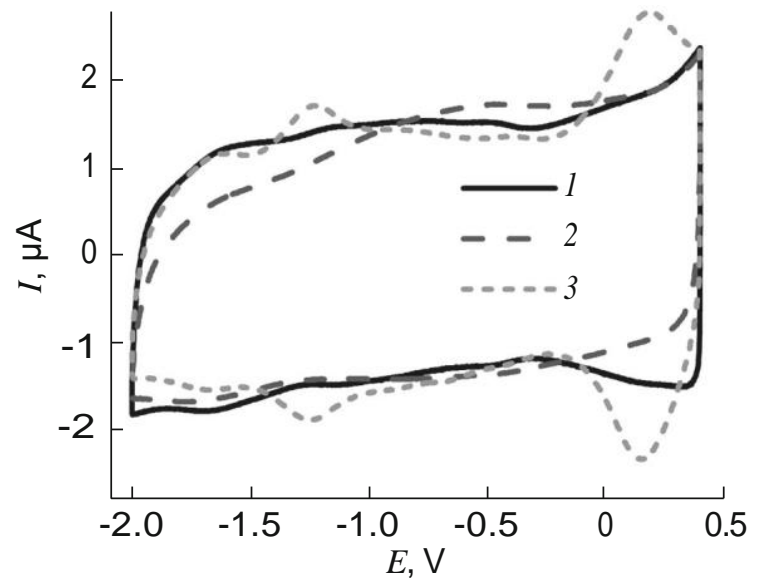

Fig. 3. Cyclic voltammetry of the polyporphine films of type II on the surface of a platinum electrode in $0.1 \mathrm{M}$ $\mathrm{Bu}_{4} \mathrm{NPF}_{6}$ (AN): (1) pMgP-II, (2) $\mathrm{pH}_{2} \mathrm{P}-\mathrm{II}$, and

(3) pCoP-Il; MgP deposition charge $9.5 \mathrm{mC} / \mathrm{cm}^{2}$; galvanostatic transformation current $I=450 \mathrm{nA}$.

trum 3) gives rise to characteristic Co peaks (curve 3) and restores the equivalence of all the four nitrogen atoms at the porphine center. Note that the oxygen content in the $\mathrm{pCoP}$-I film increases. The reason for this is higher capability of the cobalt ion to axially coordinate oxygen-containing molecules (water and atmospheric oxygen traces; the samples were transferred through an atmospheric medium).
The presence of de- and remetallation of a film of type I and the degree of these processes with preservation of the molecular structure of the polyporphine polymer chain detected from the shift of peaks on the voltammograms are also confirmed by IR, visible, and

UV spectral data (Figs. 5a and 6a). For pMgP-I and pCoP-I films whose monomer units have the same symmetry and the masses of the central ions considerably exceed the masses of the macrocycle atoms, the

IR spectra have similar (in frequency and intensity) fundamental absorption lines. According to the data of

quantum-chemical modeling, the $A$ and $B$ bands correspond to the vibrations of peripheral hydrogen atoms in the plane of the porphine rings $(A)$ and outside it $(B)$. The intense $B$ band corresponds to the deformation vibrations of the carbon-nitrogen porphine rings in the plane accompanied by the shifts of $\mathrm{N}$ atoms and opposite $\mathrm{C}$ atoms in the $\mathrm{NC}_{4}$ pyrrole rings with an immobile central metal ion. The symmetry violation on passing to unsubstituted porphine leads to a splitting of the $B$ band.

The existence of the additional band for pCoP-I in the region $1550 \mathrm{~cm}^{-1}$ is probably due to coordination of the central ion by the solvent molecules.

The replacement of the central ion without changes in the molecular structure was qualitatively confirmed by the results of spectroscopic measurements in the visible range (Fig. 6a). Demetallation of $\mathrm{pMgP}-\mathrm{I}$ with a transition to $\mathrm{pH}_{2} \mathrm{P}-\mathrm{I}$ is reflected in the spectrum as

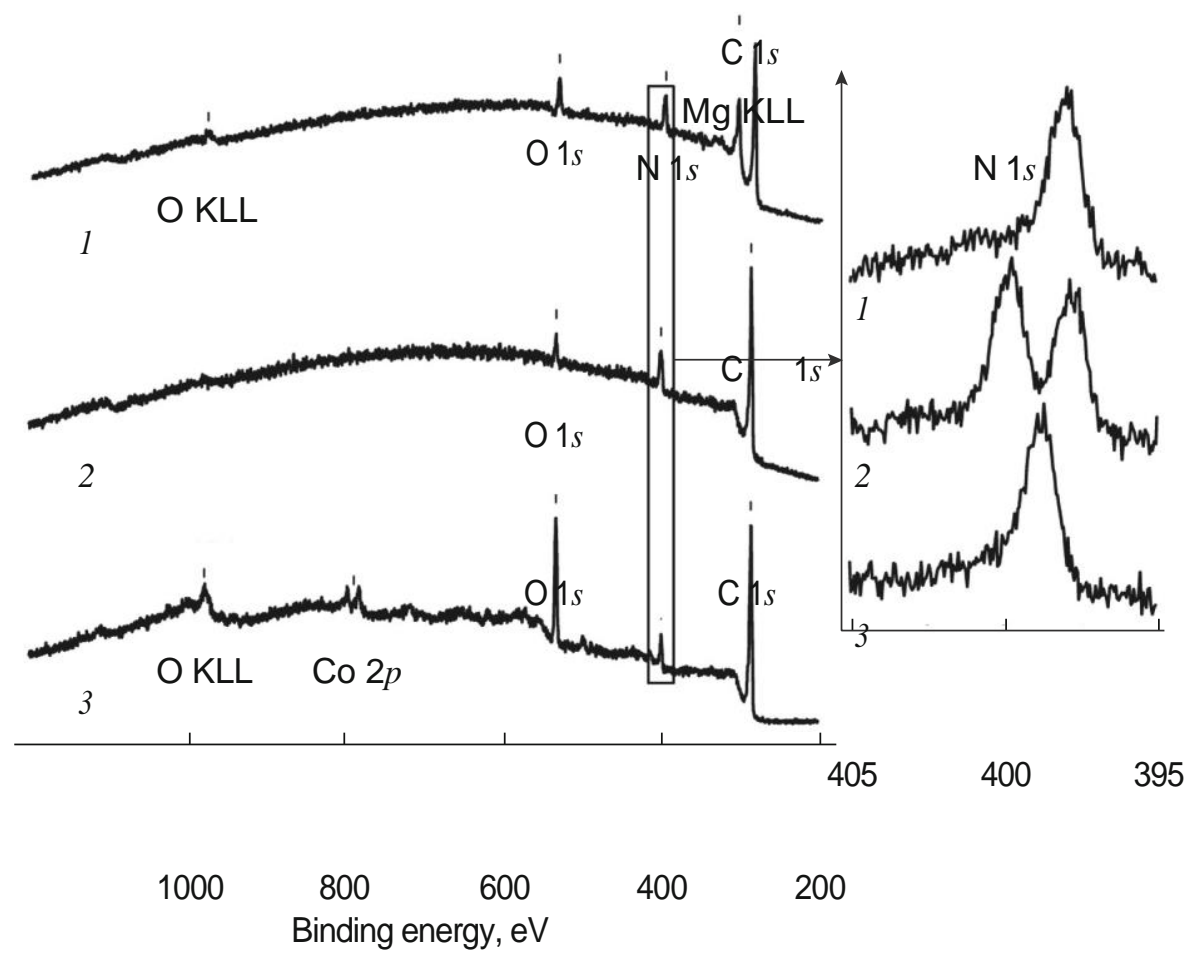

Fig. 4. X-ray photoelectron spectra of pMP-I films, where $\mathrm{M}$ is $(1) \mathrm{Mg}^{2+}$, (2) $2 \mathrm{H}^{+}$, and (3) $\mathrm{Co}^{2+}$. 
(a)

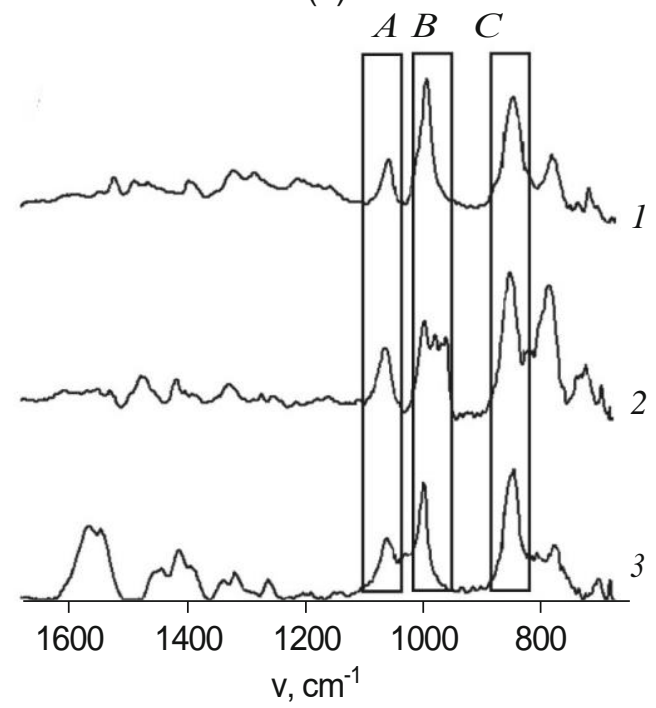

(b)

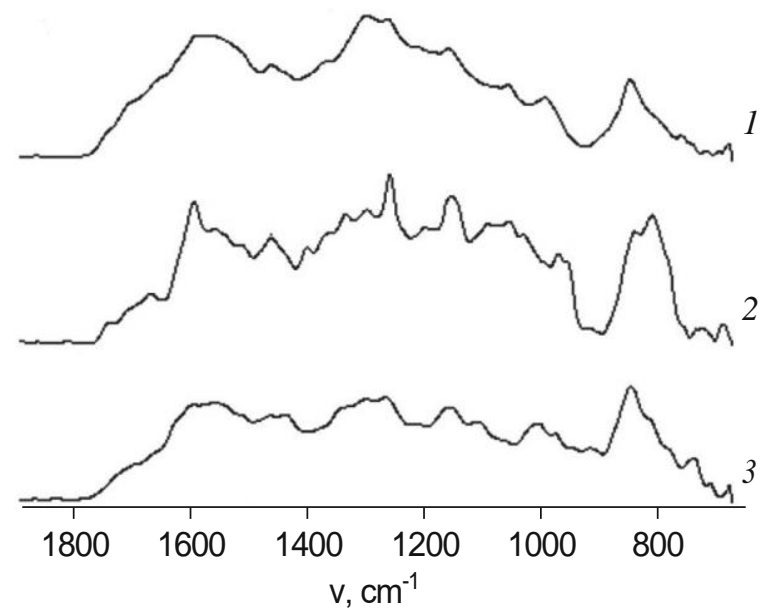

Fig. 5. Regions of the ex-situ IR (ATR) spectra of the polyporphine films on the surface of platinum foil with a thickness of $25 \mu$ m: (a) (1) magnesium polyporphine film of type I prepared by the procedure of [11] with a deposition charge of $9.5 \mathrm{mC} / \mathrm{cm}^{2}$, (2) film 1 treated with a solution of TFA in AN (1:50) for $10 \mathrm{~min}\left(\mathrm{pH}_{2} \mathrm{P}-\mathrm{I}\right)$, (3) film 2 treated with a DMF solution of $\mathrm{Co}(\mathrm{OAc})_{2} \cdot 4 \mathrm{H}_{2} \mathrm{O}$ with a concentration of $10 \mathrm{mg} / \mathrm{mL}$ for $60-90 \mathrm{~min}$ while heating it to $75-85^{\circ} \mathrm{C}$ (pCoP-I); (b) (1) pMgP-II,

(2) $\mathrm{pH}_{2} \mathrm{P}-\mathrm{II}$, and (3) pCoP-II; MgP deposition charge $9.5 \mathrm{mC} / \mathrm{cm}^{2}$; transformation current $I=450 \mathrm{nA}$.

(a)

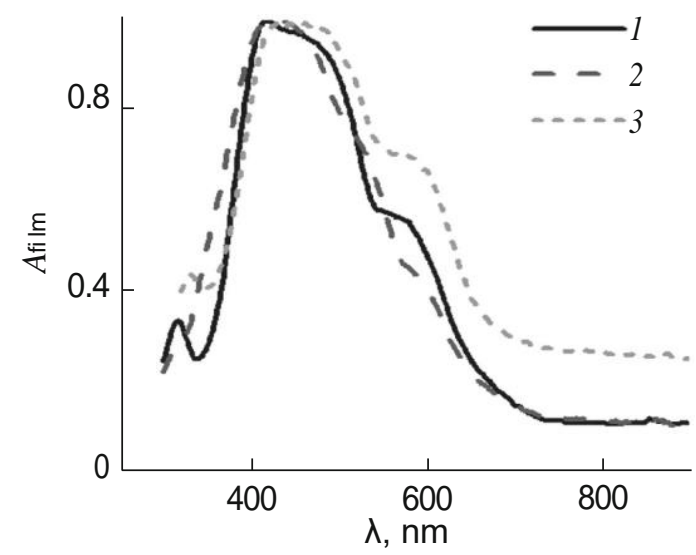

(b)

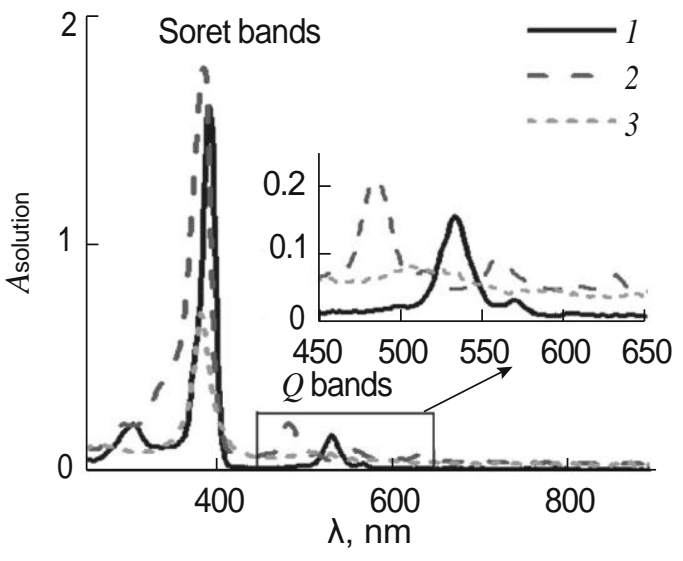

Fig. 6. Absorption spectra of the (a) optically transparent (ITO) electrode coated with (1) pMgP-I, (2) pH $\mathrm{PH}_{2} \mathrm{P}-\mathrm{I}$, and (3) pCoP-I polyporphine films and (b) AN solutions of the corresponding monomers (1) MgP, (2) $\mathrm{H}_{2} \mathrm{P}$, and (3) CoP.

an increase in the number of "steps" and redistribution of their intensities. This is explained by the lowering of the symmetry of the $\mathrm{H}_{2} \mathrm{P}$ monomer unit compared with that of $\mathrm{MgP}$, which leads to an increase in the number of various electron energy levels and, accordingly, in the number of $Q$ bands recorded in the spectra of the monomers in solution (Fig. 6b). The incorporation of the cobalt ion naturally leads to the initial form of the absorption spectrum of the film, which can also be explained by the recovery of the symmetry of the porphine ring.
IR and visible spectral studies were also performed for films of type II. The oxidative transformation of polyporphine films, which radically changes their electrochemical characteristics but does not significantly affect the macrostructure of the material (according to SEM data, see the Microscopy section below), is considerably reflected at the molecular level of polymer organization (Fig. 5b). The general tendency observed during the type I-type II transition is strong broadening of the available bands in the medium part of the spectrum $\left(800-1100 \mathrm{~cm}^{-1}\right)$ and 
$12 \mu \mathrm{m}$
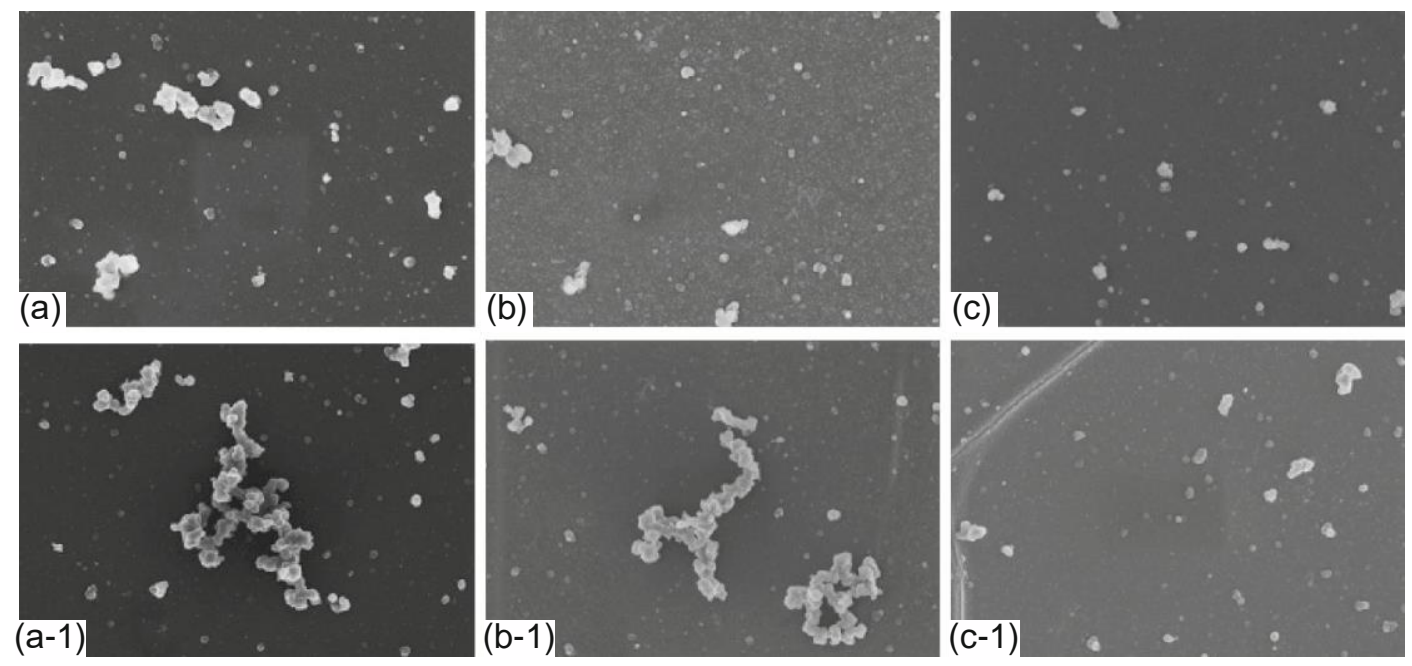

Fig. 7. SEM micrographs of the surface of the films on a platinum substrate: (a) pMgP-I, (a-1) pMgP-II, (b) $p H_{2} \mathrm{P}-\mathrm{I},(\mathrm{b}-1)$ $\mathrm{pH}_{2} \mathrm{P}-\mathrm{II}$, (c) pCoP-I, and (c-1) pCoP-II.

the appearance of new broad spectral bands in the ranges $1500-1600$ and $1200-1300 \mathrm{~cm}^{-1}$, which leads to a frequency redistribution of the absorption intensity. The fundamental lines of the polymer of type I (denoted as $A, B$, and $C$ in Fig. 5a) become weaker in the relative intensity until they almost completely merge with the "background" of bands $A$ and $B$; in contrast, the absorption in the frequency range 1500 $1200 \mathrm{~cm}^{-1}$ increases.

Thus, the removal of magnesium and introduction of cobalt in the polymer film was confirmed by XPS, $\mathrm{IR}$, and UV-visible spectroscopy. Based on the set of the obtained data we can also conclude that the structure of the porphine rings in films of type I and II did not change and that the degree of electron delocalization in the film of type II increased (expansion of the electroactivity range (Fig. 3), broadening of IR bands (Fig. 5b)).

\section{Scanning Electron Microscopy}

According to the CV data (Figs. 2 and 3), we can assume that the obtained films have a good contact with the substrate, and the chemical and electrochemical treatment of the film does not cause any negative and/or destructive effect. For more detailed studies of the morphology and structure of the deposited polyporphine films and to confirm their integrity, we performed a scanning electron microscopy study.

The micrographs (Figs. 7 and 8) show that the film surface is a uniform layer formed by the polymer particles with sizes of up to $80 \mathrm{~nm}$, which is the detection limit for the given recording mode. The surface of this layer contains irregular aggregates of larger particles (light-colored objects) with sizes of up to $400 \mathrm{~nm}$; their three-dimensional structure was confirmed by the micrograph recorded at an angle to the sample (Fig. 8a). Local energy dispersion analysis showed that both the uniform layer and the protruding parts have nearly the same chemical composition corresponding to the composition of the polymers without the $\mathrm{P}$ and $\mathrm{F}$ elements corresponding to the supporting electrolyte $\left(\mathrm{Bu}_{4} \mathrm{NPF}_{6}\right)$.

The uniform layer is assumed to consist of polymer particles that formed in the vicinity of the electrode. The appearance of larger particles on the surface of the uniform film is explained by the deposition of the polymer formed within the diffusion layer as a result of the interaction of the oligomers, which have enough time to move away to a certain distance from the electrode because of the relatively low rate of chain propagation. This, in turn, is explained by the higher stability of the magnesium porphine radical cations generated during the electrooxidation relative to those for the typical representatives of conductive polymers, whose monomers have less opportunity for delocalization of the odd electron (pyrrole, aniline, thiophene) in view of fewer conjugated bonds in the molecule.

The micrographs of all polymers revealed the similarity of morphology, which indicates that the polymer structure did not undergo any substantial changes during the replacement of the central atom and the oxidative transformation on passing to type II. Thus, the methods used do not change the film morphology and have no destructive effect. This is consistent with the preservation of the total intensity of the redox peak observed in the CV measurements, suggesting the preservation of the integrity of the film and its contact with the electrode surface. 
$2 \mu \mathrm{m}$
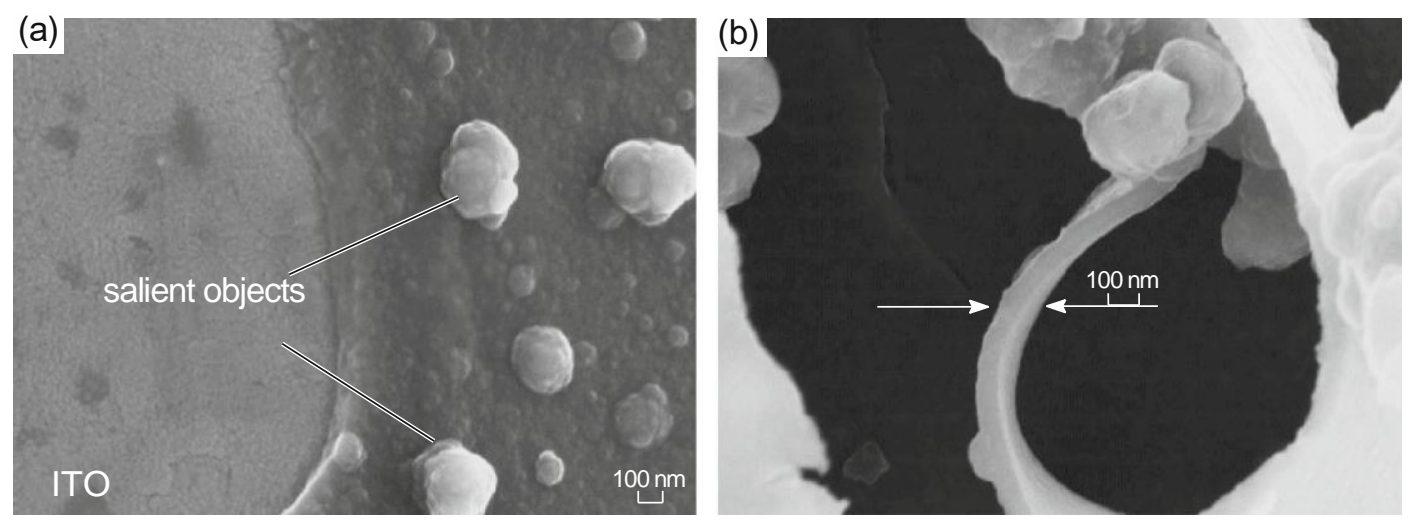

Fig. 8. SEM micrographs of polyporphine pMgP-I films on the ITO surface: (a) region of the sample with a partially removed film (left side: substrate surface); (b) transverse section of the part of the film removed from the surface.

Based on the electron microscopy data (Fig. 8b), we calculated the thickness of the deposited films and the coefficient of their relation with the deposition charge, assuming that this relation is linear:

$$
k=\frac{L S}{Q \text { dep }}=9.7 \pm 1.4 \mathrm{nmcm}{ }^{2} / \mathrm{C},
$$

where $L$ is the film thickness, $S$ is the film area, and $Q_{\text {dep }}$ is the deposition charge.

\section{Electric Conductivity Measurements}

One of the most important characteristics of electroactive films is the dependence of their conductivity (K) on the imposed potential. The method used here for determining the specific conductivity of the thin film material on the electrode surface [34] is based on measurement of the "high-frequency resistance" of a system consisting of a working disk electrode (which is small compared with the distance between its surface and other cell electrodes) coated with the film under study and set in contact with the electrolyte solution $\left(0.1 \mathrm{M} \mathrm{Bu}_{4} \mathrm{NPF}_{6}+\mathrm{AN}\right)$. A potential difference with a low amplitude $E+\delta E(\delta E=100 \mathrm{mV})$ is imposed on the system, which leads to a primary distribution of the potential and current both inside the film and in the part of solution adjacent to the film surface. Chronoamperograms with high time resolution $(2 \mu \mathrm{s})$ were recorded and showed a change in the current with time as a result of the imposition of the potential difference $\delta E$ on the electrode. Extrapolation of the linear regions of the chronoamperograms to the moment of time of the potential jump for several $E$ values in semilogarithmic coordinates $(\log I, t)$ gave the instantaneous currents, from which the total resistance of the film-solution system $R_{\text {tot }}=\delta E / I$ was calculated for each potential of the film to the jump of $E$. The region of the chronopotentiogram used for extrapolation corresponded to the time interval of 20-30 $\mu$ s; i.e., the resistances contained the "high-frequency" conductivity of the material. Then the film resistance $\left(R_{\mathrm{f}}\right)$ was isolated from the total resistance of the film-solution system $\left(R_{\text {tot }}\right)[34]$, and the resulting film resistances were recalculated for the specific conductivity (Fig. 9)

by the equation $\mathrm{K}=L /\left(S R_{\mathrm{f}}\right)$.

The resulting conductivities of the pMgP-I, $\mathrm{pH}_{2} \mathrm{P}-\mathrm{I}$, and $\mathrm{pCoP}-\mathrm{I}$ films confirm the correlation between the electroactivity and conductivity of the polymer matrix observed for the majority of electroactive polymer materials. In the range of potentials corresponding to high electroactivity of the films, the resistance of the electrode-film system becomes close to that of the electrode not coated with the film; i.e., their values coincide to an accuracy of the experimental error. For this reason, the sensitivity of the conductivity measurement method used with allowance for the conditions (electrode area, solution resistance, and film thickness) has an upper bound of $0.01(\mathrm{Ohm} \mathrm{m})^{-1}$.

The dependences of the conductivity of the pMgP-I, $\mathrm{pH}_{2} \mathrm{P}-\mathrm{I}$, and $\mathrm{pCoP}-\mathrm{I}$ films on their redox state (Fig. 9) are similar in shape; the growth of conductivity correlates with the electroactivity level on the voltammogram of the corresponding polymer. In the discharged state, the $\mathrm{pH}_{2} \mathrm{P}-\mathrm{I}$ film showed the lowest conductivity, while the minimum conductivities of the metallated forms are close. This can be explained by the formation of a denser polymer layer in the discharged state for metal-free polyporphine because it has no solvent molecules coordinated by the central ions. The presence of these molecules for metallated films leads to a looser structure of polymers with possible inclusions of the components of the supporting electrolyte and with facilitated transfer of these components under the action of the field gradient, which is just the reason for the decrease in their high-frequency resistance in the neutral state. 
(a)

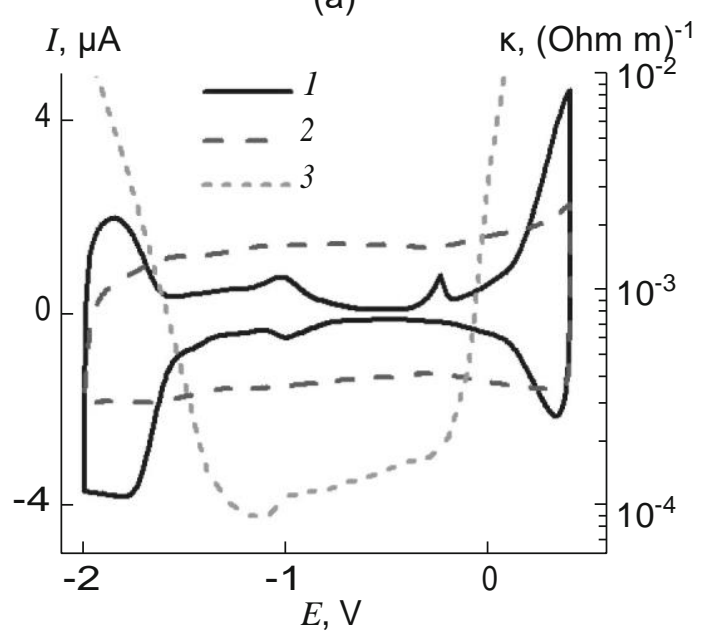

(b)

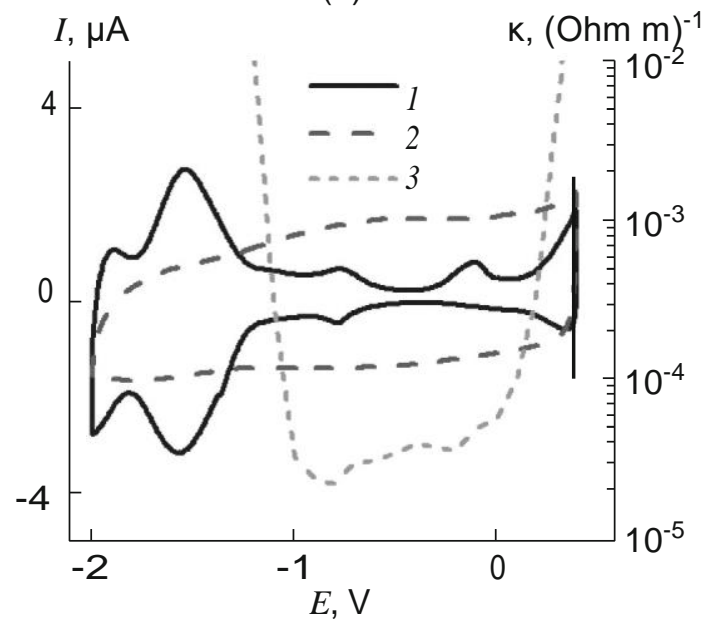

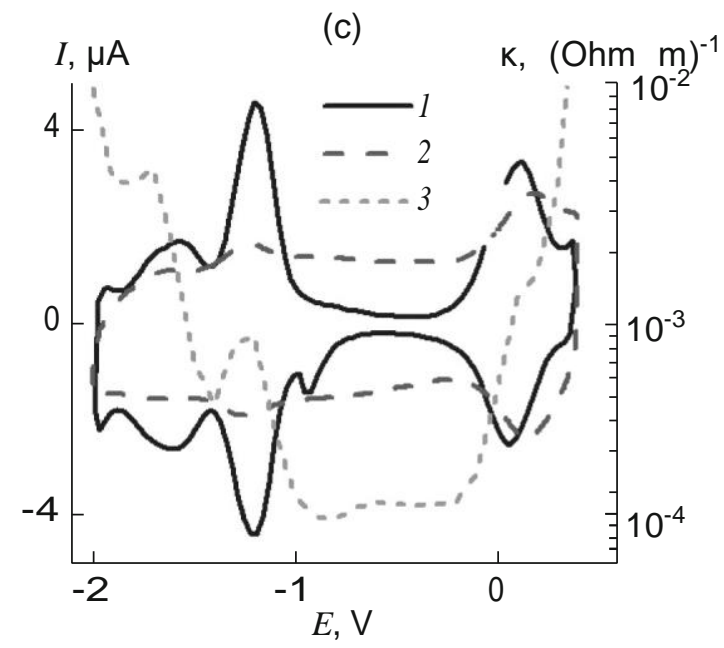

Fig. 9. Cyclic voltammetry of polyporphine films of type I with different central atoms (pMP-I, curve 1), type II (pMP-II, curve 2) and conductivity of the films of type I (curve 3) on the surface of the platinum electrode in $0.1 \mathrm{M} \mathrm{Bu} 4 \mathrm{NPF}_{6}(\mathrm{AN}) ;(\mathrm{a}) \mathrm{M}=\mathrm{Mg}{ }^{2+}$, (b) $\mathrm{M}=2 \mathrm{H}^{+}$, and (c) $\mathrm{M}=\mathrm{Co}^{2+}$.

A certain difference in the character of the dependence $\mathrm{k}-E$ is observed for cobalt polyporphine (Fig. 9c). In the potential range of the $\mathrm{Co}(\mathrm{I}) / \mathrm{Co}(\mathrm{II})$ and $\mathrm{Co}(\mathrm{II}) / \mathrm{Co}$ (III) redox transitions, there is local growth of conductivity. This suggests that along with the charge transport along the conjugated m-electron system of the polymer in the range of redox transition potentials, the contribution of the charge transfer mechanism appears which is characteristic of redox polymers, i.e., the electron transfer between the neighboring sites (between the cobalt ions inside the polymer in this case) with different degrees of oxidation.

According to the CV data (Fig. 3), the films of type II are electroactive over the whole range of potentials under study. The total resistances of the film-solution system determined by the potential difference method coincide, within the measurement error, with the results for the electrode not coated with the film. Thus, we can conclude that the conductivity is higher than $0.01(\mathrm{Ohm} \mathrm{m})^{-1}$ for all the films under study subjected to oxidative transformation into type II irrespective of the value of the imposed potential. This is explained by the removal of hydrogen atoms in the beta positions of the neighboring porphine macrocycles in the chain, which hindered the ideal $f$ lattening of the chain in the polymer of type I and by the additional fixation of these macrocycles relative to one another (due to the formation of new beta-beta bonds) in one plane, i.e., in the position that favors the overlap of their $\pi$-electron systems. This, in turn, increases the length of conjugation and the degree of electron delocalization, leading to an increase in the conductivity of the polymer in any redox state.

\section{Catalysis of Oxygen Electroreduction}

The electroreduction of oxygen is one of the most important electrochemical processes currently used in 
(a)
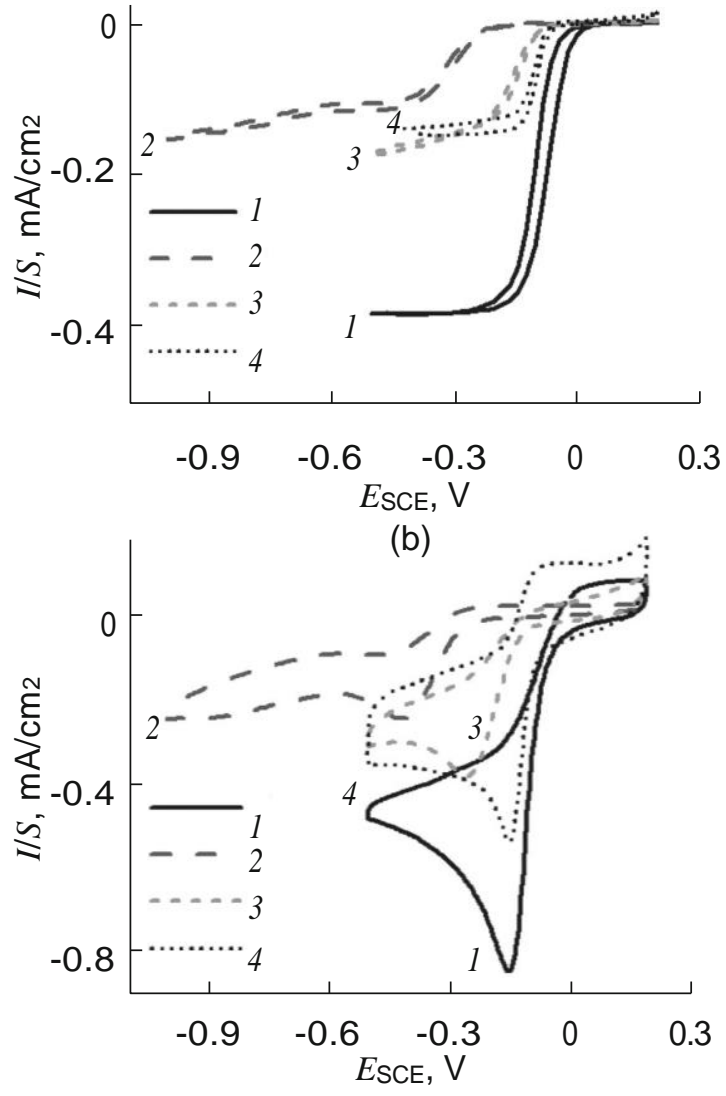

Fig. 10. (a) Stationary curves and (b) cyclic voltammograms of the $\mathrm{Pt}$ (curve 1 ) and glassy carbon (curve 2) electrodes without a film and glassy carbon electron coated with a pCoP-I (curve 3) or pCoP-II (curve 4) film, $0.1 \mathrm{M} \mathrm{NaOH}$ in $\mathrm{H}_{2} \mathrm{O}$.

the majority of fuel cells [22-24]. Because of its multielectron character, it occurs via several electrochemical and chemical stages. The final product may be water molecules (in an acid medium), hydroxyl ions $\mathrm{OH}^{-}$(in an alkaline medium), hydrogen peroxide $\mathrm{H}_{2} \mathrm{O}_{2}$, or its ionic form $\mathrm{HO}_{2}^{-}$depending on the electrode material and $\mathrm{pH}$ of solution.

The most important characteristic of the process that determines its energy efficiency is the potential at which the process is fast enough, for example, the half-wave potential for the stationary polarization curves at which the reaction rate is half of its limit controlled only by the transport of reagents and products. The electrode material that provides the best (highest positive) value of this potential is platinum, for which the half-wave potential at $\mathrm{pH} 13$ is close to $-0.1 \mathrm{~V}$ (curve 1, Fig. 10a), while for the inert substrate (glassy carbon), the potential shifted by $200-300 \mathrm{mV}$ toward the negative values (curve 2, Fig. 10a).

The stationary polarization curves presented in Fig. 10a for films of both types: pCoP-I (curve 3) and pCoP-II (curve 4) deposited on the surface of a glassy carbon electrode confirm the expected catalytic activity of these materials in the electroreduction of $\mathrm{O}_{2}$. Growth of current as a function of the potential has the form of a wave whose potential $E_{1 / 2}$ is close to the value of this parameter for the platinum electrode for both films.

Note that this wave corresponds to the potential range in which the electric conductivity of the film of type I is already high enough (curve 1, Fig. 9c) to pro-

vide effective transport of the electronic charge between the reaction sites in the film and substrate. At the same time, the conductivity of this film under equilibrium conditions at higher negative potentials should drastically decrease (curve 1, Fig. 9c), hindering the charge transport. On the curve in Fig. 10, however, the current does not decrease unless it reached at least $-0.45 \mathrm{~V}$. It may be concluded that the film is in a nonequilibrium state: the oxygen molecules react with the surface porphine groups, making them charged positively, and then the corresponding hole charge carriers move to the substrate surface (glassy carbon) and are discharged on it.

There is no such problem for the film of type II because this polymer has high electron conductivity over a very wide range of potentials (curve 2, Fig. 9c), including the range shown in Fig. 10a.

Similar results were obtained by CV under the conditions of only the diffuse mechanism of reagent and product transport (Fig. 10b). The cathode wave was observed in all instances, which corresponds to much smaller negative potentials for cobalt polyporphines than for glassy carbon. For the film of type II, this wave lies at slightly higher negative values than for platinum.

The data of Fig. 10 correspond to an alkaline solution ( $\mathrm{pH}$ 13). Similar studies were also performed for a neutral solution $\left(0.1 \mathrm{M}\left(\mathrm{C}_{2} \mathrm{H}_{5}\right)_{4} \mathrm{NClO}_{4}\right.$ in $\left.\mathrm{H}_{2} \mathrm{O}\right)$. In this case, the peak potentials of oxygen electroreduction on the platinum and modified electrodes were also found to be close.

Thus, we can conclude that the pCoP-I and pCoP-II films possess catalytic activity with respect to oxygen and are of interest as platinum-free catalysts of oxygen electroreduction. In this context, further studies of these materials are needed in view of their promising potential applications.

\section{ACKNOWLEDGMENTS}

This study was financially supported by the Russian Scientific Foundation (grant no. 14-13-01244).

\section{REFERENCES}

1. Handbook, Kadish, K.M., Smith, K.M., and Guilard, R., Eds., vols. 1-20, Academic Press, 2000.

2. Lucas, D., Dime, A.K.D., Rousselin, Y., and Mugnier, Y., Dalton Trans., 2010, vol. 39, p. 2404. 
3. de Medeiros, M.A.C., Gorgy, K., Deronzier, A., and Cosnier, S., Mater. Sci. Eng., C, 2008, vol. 28, p. 731.

4. Tesakova, M.V., Popov, I.A., Sheinin, V.B., Semeikin, A.S., Parfenyuk, V.I. and Koifman, O.I., Macroheterocycles, 2013, vol. 6, p. 152.

5. Zhutaeva, G.V., Tarasevich, M.R., Radina, M.V., and Chernyshova, I.S., Russ. J. Electrochem., 2009, vol. 45, p. 1080.

6. Tarasevich, M.R., Beketaeva, L.A., Efremov, B.N., Zagudaeva, N.M., Kuznetsova, L.N., Rybalka, K.V., and Sosenkin, V.E., Russ. J. Electrochem., 2004, vol. 40, p. 542.

7. Bogdanovskaya, V.A., Beketaeva, L.A., Rybalka, K.V., Efremov, B.N., Zagudaeva, N.M., Sakashita, M., lidzima, T., and Ismagilov, Z.R., Russ. J. Electrochem., 2008, vol. 44, p. 293.

8. Vershinina, I.A., Gornukhina, O.V., Pimkov, I.V., and Golubchikov, O.A., Izv. Vyssh. Uchebn. Zaved., Khim. Khim. Tekhnol., 2009, vol. 52, p. 83.

9. Vorotyntsev, M.A., Konev, D.V., Devillers, C.H., Bezverkhyy, I., and Heintz, O., Electrochim. Acta, 2010, vol. 55, p. 6703.

10. Vorotyntsev, M.A., Konev, D.V., Devillers, C.H., Bezverkhyy, I., and Heintz, O., Electrochim. Acta, 2011, vol. 56, p. 3436.

11. Konev, D.V., Devillers, C.H., Lizgina, K.V., Baulin, V.E., and Vorotyntsev, M.A., J. Electroanal. Chem., 2015, vol. 737, p. 235.

12. Yamaguchi, Y., Int. J. Quantum Chem., 2009, vol. 109, p. 1584.

13. Konev, D.V., Vorotyntsev, M.A., Devillers, C.H., Zyubina, T.S., Zyubin, A.S., Lizgina, K.V., and Volkov, A.G., Russ. J. Electrochem., 2013, vol. 49, p. 753.

14. Konev, D.V., Devillers, C.H., Lizgina, K.V., Zyubina, T.S., Zyubin, A.S., Valkova, L.A., and Vorotyntsev, M.A., Electrochim. Acta, 2014, vol. 122, pp. 3-10.

15. Li, J., Diers, J.R., Seth, J., Yang, S.I., Bocian, D.F., Holten, D., and Lindsey, J.S., Org. Chem., 1999, vol. 64, p. 9090.

16. Adler, A.D., Longo, F.R., Kampas, F., and Kim, J., J. Inorg. Nucl. Chem., 1970, vol. 32, p. 2443.

17. Ogawa, T., Nishimoto, Y., Yoshida, N., Ono, N., and Osuka, A., Angew. Chem., Int. Ed. Engl., 1999, vol. 38, p. 176.
18. Wu, Z.S., Chen, L., Liu, J., Parvez, K., Liang, H., Shu, J., Sachdev, H., Graf, R., Feng, X., and Mullen, K., Adv. Mater., 2014, vol. 26, p. 1450.

19. Tarasevich, M.R. and Radyushkina, K.A., in Kataliz $i$ elektrokataliz metalloporfirinami (Catalysis and Electrocatalysis with Metal Porphyrines), Moscow: Nauka, 1982, p. 168.

20. Tarasevich, M.R. and Orlov, S.B., in Elektrokhimiya polimerov (Polymer Electrochemistry), Moscow: Nauka, 1990, p. 238.

21. Tarasevich, M.R., Radyushkina, K.A., and Bogdanovskaya, V.A., in Elektrokhimiya porfirinov (Porphyrine Electrochemistry), Moscow: Nauka, 1991.

22. Zagal, J.H., Bedioui, F., and Dodelet, J.P., N4-Macrocyclic Metal Complexes, New York: Springer, 2006.

23. Han, A., Jia, H., Ma, H., Ye, S., Wu, H., Lei, H., and Du, P., Phys. Chem. Chem. Phys., 2014, vol. 16, p. 11224.

24. Hijazi, I., Bourgeteau, T., Cornut, R., Morozan, A., Filoramo, A., Leroy, J., and Campidelli, S., J. Am. Chem. Soc., 2014, vol. 136, p. 6348.

25. Schaferling, M. and Bauerle, P., J. Mater. Chem., 2004, vol. 14, p. 1132.

26. Cosnier, S., Gondran, C., Wessel, R., Montforts, F.P., and Wedel, M., J. Electroanal. Chem., 2000, vol. 488, p. 83.

27. Bedioui, F., Devynck, J., and Bied-Charreton, C., Acc. Chem. Res., 1995, vol. 28, p. 30.

28. Liddell, P.A., Gervaldo, M., Bridgewater, J.W., and Keirstead, A.E., Chem. Mater., 2008, vol. 20, p. 135.

29. Paul-Roth, C., Rault-Berthelot, J., Simonneaux, G., and Poriel, C., J. Electroanal. Chem., 2006, vol. 597, p. 19.

30. Medard, C., Lefevre, M., Dodelet, J.P., Jaouen, F., and Lindbergh, G., Electrochim. Acta, 2006, vol. 51, p. 3202.

31. Konev, D.V., Istakova, O.I., Sereda, O.A., Shamraeva, M.A., Devillers, C.H., and Vorotyntsev, M.A., Electrochim. Acta, 2015, vol. 179, p. 315.

32. Yamaguchi, Y., J. Chem. Phys., 2002, vol. 117, p. 9688.

33. Tsuda, A. and Osuka, A., Adv. Mater., 2002, vol. 14, p. 75.

34. Vorotyntsev, M.A. and Konev, D.V., Electrochim. Acta, 2011, vol. 56, p. 9105. 